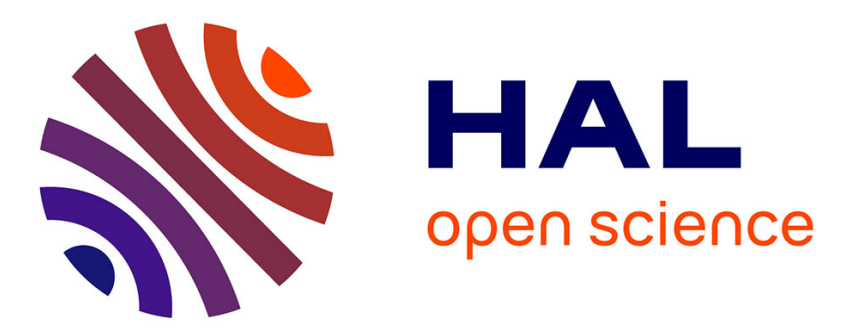

\title{
Symptom evaluation during the methacholine test: Does it add to the interpretation of the test results based on the PC20FEV1?
}

\author{
Abraham B. Bohadana, Pascal Wild, Gabriel Izbicki
}

\section{> To cite this version:}

Abraham B. Bohadana, Pascal Wild, Gabriel Izbicki. Symptom evaluation during the methacholine test: Does it add to the interpretation of the test results based on the PC20FEV1?. The Clinical Respiratory Journal, In press, 10.1111/crj.12701 . hal-01684103

\section{HAL Id: hal-01684103 https://hal.science/hal-01684103}

Submitted on 15 Jan 2018

HAL is a multi-disciplinary open access archive for the deposit and dissemination of scientific research documents, whether they are published or not. The documents may come from teaching and research institutions in France or abroad, or from public or private research centers.
L'archive ouverte pluridisciplinaire HAL, est destinée au dépôt et à la diffusion de documents scientifiques de niveau recherche, publiés ou non, émanant des établissements d'enseignement et de recherche français ou étrangers, des laboratoires publics ou privés. 


\section{REVISED VERSION FINAL}

\section{Symptom evaluation during the methacholine test: Does it add to the interpretation of the test results based on the PC20FEV1?}

Abraham B. BOHADANA ${ }^{1 \oplus}, \mathrm{MD}$, Pascal WILD ${ }^{2}, \mathrm{PhD}^{\circ}$ and Gabriel IZBICKI ${ }^{1}, \mathrm{MD}$

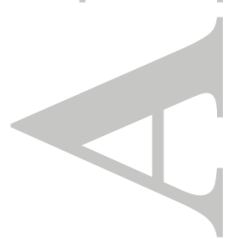

Funding: This study was funded by an unrestricted grant from Novartis, Israel

Conflict of interest: The authors have no conflicts of interest to declare.

Short title: Symptom evaluation during the methacholine test

1. Respiratory Research Unit, (RUPI) Pulmonary Institute, Shaare Zedek Medical Center, 12 Baiyt Street, 91031 Jerusalem, Israel. Affiliated with the Hadassah School of Medicine, Hebrew University of Jerusalem.

2. INRS - National Research and Safety Institute, 1 rue du Morvan, CS 60027, 54519

Vandoeuvre Cedex, France. Electronic address: pascal.wild@inrs.fr.

\section{Correspondence:}

Abraham Bohadana, MD.

Pulmonary Institute, Shaare Zedek Medical Center, 12 Baiyt Street, 91031 Jerusalem, Israel.

abohadana@szmc.org.il

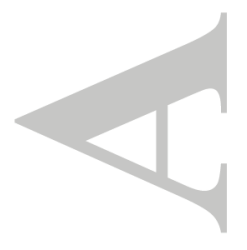

This article has been accepted for publication and undergone full peer review but has not been through the copyediting, typesetting, pagination and proofreading process which may lead to differences between this version and the Version of Record. Please cite this article as an 'Accepted Article', doi: 10.1111/crj.12701 


\section{Abstract}

Purpose: Conventionally, symptoms occurring during the methacholine test are not taken into account when interpreting the test results. We examined whether the evaluation of methacholine-induced symptoms (MIS) added to the test interpretation based on the PC20FEV1 by assessing their prevalence, their similarity with symptoms justifying referral and their relationship with airway responsiveness.

Methods: Eighty-two patients with suspected asthma completed a questionnaire of symptoms and underwent bronchial challenge with methacholine. Based on MIS and airway responsiveness (responders=PC20FEV1 $1<8 \mathrm{mg} / \mathrm{mL}$ ), subjects were classified as asymptomatic non-responders (ANRs), asymptomatic responders (ARs), symptomatic non-responders (SNRs) and symptomatic responders (SRs). Airway responsiveness for all subjects, including non-responders (i.e. fall in FEV1<20\%), was assessed by the methacholine concentration response-slope (MCRS) obtained using all points of the curve.

Results: ARs ( $n=6)$ were poor-perceivers of bronchoconstriction. SNRs ( $n=16)$ did not differ from SRs $(\mathrm{n}=34)$ in any clinical parameter, including the proportion of subjects $(\sim 80 \%)$ whose methacholine test reproduced symptoms justifying referral. In turn, SNRs differed significantly from ANRs $(n=26)$ by having lower baseline FEV1 $(p=0.005)$, more physiciandiagnosed asthma $(\mathrm{p}<0.001)$, more use of respiratory medication $(\mathrm{p}=0.032)$, and relatively greater responsiveness as manifested by a steeper MCRS $(\mathrm{p}<0.001)$.

Conclusions: The occurrence of asthma-like symptoms during the methacholine test was associated with milder airway hyperresponsiveness that would go unnoticed by the PC20FEV1. This finding suggests that SNRs should not be merely classified as having normal responsiveness, as currently recommended, but further assessed for airway inflammation. Our results helped planning a longitudinal study to investigate the prognostic validity of this approach.

\section{Word counting: 247}

Key words: methacholine challenge test; symptom perception; "asthma-like" symptoms; asthma; airway hyperresponsiveness. 


\section{Introduction}

Asthma is defined by the history of recurrent episodes of dyspnea, chest tightness, coughing and/or wheezing, combined with expiratory airflow limitation that is reversible in response to a bronchodilator ${ }^{1}$. In subjects with typical asthma symptoms and normal spirometry, one option is to perform a methacholine challenge test (MCT) in order to assess airway hyperresponsiveness (AHR) ${ }^{1}$. Conventionally, a positive test is defined as the provocative concentration of methacholine causing a $\geq 20 \%$ fall in forced expiratory volume in one second (PC20FEV1) $<8$ or $<16 \mathrm{mg} / \mathrm{mL}$, and a negative test as a non-response to the highest concentration $^{2}$. In contrast with the definition of asthma, the interpretation of the MCT results relies solely on the percent drop in FEV1, without consideration of the symptoms justifying referral or those that may occur during the test. Although very popular, this approach ignores prior studies emphasizing the relevance of symptom evaluation during provocation tests $^{3-6}$. Furthermore, since it can only be assessed in subjects with AHR, a threshold index like the PC20FEV1 is of limited value to examine the relationship between symptoms and responsiveness at sub-threshold (i.e. <20\%) levels of fall in FEV1. This has practical importance because studies using non-censored measures of responsiveness such as the dose-response slope (DRS) found a significant association between asthma symptoms and airway responsiveness both above and below the threshold of $\mathrm{AHR}^{7-8}$.

In this study, we investigated whether the evaluation of methacholine-induced symptoms (MIS) in a population of adults with suspected asthma added to the interpretation of the test results based on the PC20FEV1. To do so we determined the prevalence of MIS in responders and non-responders, checked their similarity with symptoms justifying referral, and examined their relationship with airways responsiveness assessed for all individuals, including those who did not reach the threshold of AHR. 


\section{Methods}

\section{Patients}

The study was made up of 82 consecutive patients undergoing MCT at the Pulmonary Institute of the Shaare Zedek Medical Center, in Jerusalem. General practitioners, allergists and pulmonary specialists referred the subjects as part of the investigation of symptoms compatible with asthma. All subjects stopped short-acting bronchodilators for at least 8 hours, long-acting beta-agonists for at least 12 hours, and inhaled corticosteroids for at least 1 week before the MCT. No patient reported acute respiratory infections in the preceding 6 weeks, The hospital's Ethical Committee approved the study, but a consent form was not deemed necessary because the data to be collected were already included in the clinical MCT protocol.

\section{Methacholine Challenge Testing}

The MCT was done using the two-minute tidal breathing protocol ${ }^{2}$. At baseline, at least three reproducible measures of forced vital capacity $(\mathrm{FVC})$ and FEV1 were obtained ${ }^{9}$. Then the subject inhaled $0.9 \%$ saline followed by doubling concentrations of methacholine $(0.03$ $\mathrm{mg} / \mathrm{mL}$ to $8 \mathrm{mg} / \mathrm{mL}$ ) until a fall in baseline FEV1 by at least $20 \%$ occurred, or the last concentration of methacholine was inhaled. Aerosols (particle size $=3.6$ microns) were generated from a Hudson RCI micro mist nebulizer (Teleflex-Hudson RCI, USA) with an output of $0.13 \mathrm{~mL} / \mathrm{min}$ and were inhaled through the mouth through a mouthpiece for 2 minutes by means of tidal breathing. The PC20FEV1 was obtained from the log-dose response curve and AHR was defined as a PC20FEV1 $<8 \mathrm{mg} / \mathrm{mL}^{2}$. At end-test, responders and subjects reporting MIS inhaled four puffs of salbutamol (400 $\mu \mathrm{g}$ ) from a metered dose inhaler. The methacholine concentration-response slope was computed by applying a mixed model through all data points obtained by plotting the percent fall in FEV1 from prechallenge FEV1 divided by the amount of methacholine inhaled.

\section{Questionnaire}

Smoking history, respiratory health, the reason for the test, pre-challenge symptoms and symptoms occurring during the test were evaluated using the ATS questionnaire for MCT $^{2}$ (Appendix). At baseline and immediately after the administration of each methacholine 
concentration, before spirometry, subjects were asked whether they were experiencing symptoms of either dyspnoea, chest tightness, cough or wheezing. In case of positive response, they were asked whether the symptoms were similar to those for which they consulted with a physician and that motivated the test. In addition, an experienced observer $(\mathrm{AB})$ assessed wheeze sounds occurring during the MCT objectively by placing an electronic stethoscope (Littman Model 4000) over the patient's trachea, $2 \mathrm{~cm}$ above the suprasternal $\operatorname{notch}^{10-11}$.

\section{Clinical responsiveness}

Based on MIS and airway responsiveness, subjects were classified into four groups of clinical responsiveness: 1. “Asymptomatic non-responders” (ANRs): no symptom and/or wheeze by auscultation during MCT; PC20FEV1 $\geq 8 \mathrm{mg} / \mathrm{mL} ; 2$."Asymptomatic responders" (ARs): no symptom and/or wheeze by auscultation during MCT; PC20FEV $1<8 \mathrm{mg} / \mathrm{mL}$; 3.“Symptomatic non-responders” (SNRs): $\geq 1$ symptom and/or wheeze by auscultation during MCT; PC20FEV1 $\geq 8 \mathrm{mg} / \mathrm{mL}$; and 4."Symptomatic responders" (SRs): $\geq 1$ symptom and/or wheeze by auscultation during MCT; PC20FEV1<8mg/mL.

\section{Statistical analysis}

Statistical analysis was carried out using the Stata Package (Stata 13, College Station, TX, USA). Demographic characteristics were summarised using descriptive statistics, including means and standard deviations. To explore whether the pre-test characteristics were predictive of the outcome of the MCT, we modelled separately being a reactor, experiencing symptoms during the test and the combination of the two outcomes with simple logistic regressions including each pre-challenge characteristic at a time. In addition, three of the post-hoc groups namely SRs, SNRs and ANRs were compared using Fisher's exact test or one-way analysis of variance (ANOVA) as relevant. To assess the relationship between MIS and airway responsiveness below the level of AHR (i.e. at $<20 \%$ fall in FEV1) we used a mixed model to compare the methacholine concentration-response curve slope (MCRS) of SNRs with that of ANRs over the whole range of the MCRS curve. The end-test FEV1 of SNRs and ARs was compared using t-tests. Finally, multiple logistic regression analysis was used to determine the factors associated with the occurrence of asthma-like symptoms during the MCT. The discrimination power of the fitted logistic model was expressed by the area 
under the curve (AUC) of receiver operating characteristic (ROC) curves. A p-value of less than 0.05 was considered significant.

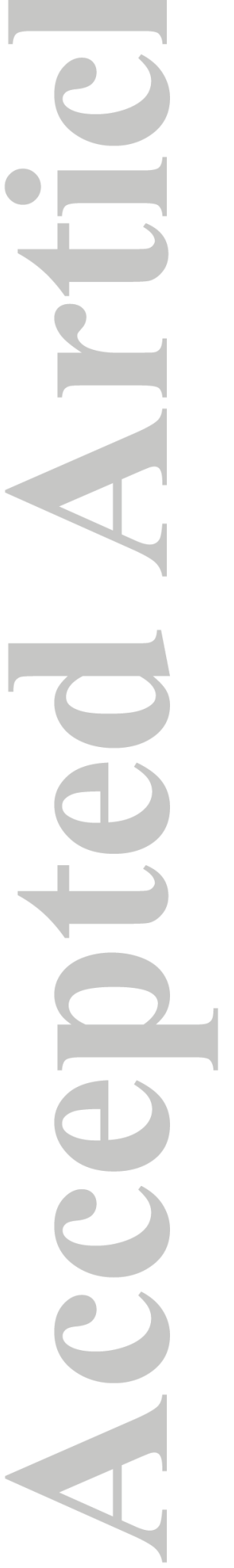




\section{Results}

Of the 82 patients studied, $26(31.7 \%)$ were classified as ANRs; 6 (7.3\%) as ARs; 16 $(19.5 \%)$ as SNRs and $34(41.5 \%)$ as SRs. Table 1 shows the baseline characteristics of the four groups. Being a female was significantly associated with both being a responder and being a symptomatic responder. A lower baseline FEV1 was significantly associated with symptoms during MCT and with being a SR, but not with being a responder. Finally, dyspnoea as a reason for the test was strongly and significantly associated with symptoms during the MCT, being a responder, and being a SR. No other associations were statistically significant.

\section{Pre-test characteristics}

Table 2 shows the pre-challenge characteristics of the four groups. Reporting previous, physician-diagnosed asthma and all respiratory symptoms in the two weeks preceding the test - except chest tightness - were related to symptoms during MCT and being a SR. These associations were less strong and not always significant with being a responder. Use of respiratory medicine was significantly related to the three outcomes, but this association was strongest for symptoms during MCT.

Compared with ANRs, SRs presented significantly lower baseline FEV1 ( $p=0.002)$, more dyspnoea as a reason for performing the MCT (0.039), more physician-diagnosed asthma in the past $(\mathrm{p}=0.001)$ and more recent symptoms of dyspnoea $(\mathrm{p}<0.001)$, wheeze $(\mathrm{p}=0.03)$, or any symptom $(p=0.02)$, as well as more use of pulmonary medication $(p<0.001)$. In turn, SNRs looked very similar to SRs, no differences between the two groups emerging whatever the parameter considered ( $\mathrm{p}$ values between 0.14 for pre-test dyspnoea, and 0.98 for baseline FEV1). Conversely, SNRs differed from ANRs by showing significantly lower baseline FEV1 $(\mathrm{p}=0.005)$, greater proportion of subjects reporting physician-diagnosed asthma $(p<0.001)$, and a greater proportion of subjects using respiratory medication $(p=0.03)$; for wheeze as a reason for the test the difference was of borderline significance $(p=0.06)$.

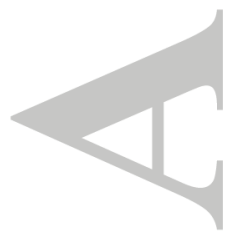




\section{Symptoms occurring during the MCT}

Dyspnoea and wheeze detected by auscultation (Table 3) were, by far, the most common findings in each group, followed by cough, subjective wheeze, and chest tightness. SRs and SNRs were similar in the proportion of subjects reporting symptoms during the test and in the proportion of subjects who recognized these symptoms as similar to those justifying referral (SNRs=81.2\% vs. SRs=79.4\%; $\mathrm{p}=1.000)$. Figure 1 shows that the lower the dose of methacholine necessary to trigger symptoms the more likely the subjects were to be responders. Figure 2 shows that no linear relationship existed between the magnitude of percent fall in FEV1 and the onset of symptoms: some subjects presented symptoms at negligible falls in FEV1, while others remained asymptomatic until the FEV1 had fallen by values as great as $40 \%$.

\section{Relationship between MIS and airway responsiveness below the threshold of AHR}

This was evaluated by assessing the differences between the MCRS of the two groups of non-responders. As shown in figure 3, SNRs had significantly steeper MCRS $(\mathrm{p}<0.001)$ values than ANRs a finding indicating relatively greater airway responsiveness in SNRs. Accordingly, SNRs had significantly greater mean percent fall in FEV1 at end-test $(14.0 \pm 4.7)$ than ANRs $(8.6 \pm 5.9)(\mathrm{p}=0.003)$.

\section{Predictors of "asthma-like" symptoms during MCT}

Multiple logistic regression analysis showed that three factors were significantly associated with the occurrence of MIS: (a) physician-diagnosed asthma in the past; (b) baseline FEV1 $\%$ predicted; and (c) percent fall in FEV1 at end-test (Table 4). The discrimination ability of the logistic model, assessed by means of ROC curve, showed a curve close to the optimal left upper corner. The resulting AUC was 0.9494, indicating the excellent discrimination ability for the model (Figure 4).

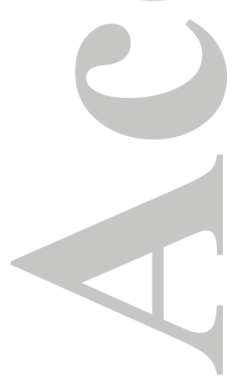




\section{Discussion}

In an outpatient population of adult patients referred for MCT because of suspected asthma, we found that $85 \%$ of the responders and $36 \%$ of the non-responders experienced methacholine-induced symptoms during the test, and that in $\sim 80 \%$ of the subjects in each group these symptoms corresponded to the symptoms justifying referral. Furthermore, among non-responders, SNRs were found to exhibit a steeper methacholine concentrationresponse slope than ANRs indicating a relative increase in airway responsiveness in the former group. These results suggest a possible role for symptom evaluation during the methacholine test.

The observed high proportion of SRs is in keeping with studies showing high prevalence rates of histamine $e^{3,12,13}$ or methacholine $e^{4,14,15}$ induced symptoms in responders. It is also in agreement with studies showing that AHR is not only associated with paroxysms of bronchospasm and bronchial irritability ${ }^{16}$ but also a major determinant of the clinical manifestations of asthma ${ }^{17,18}$. Finally, our data confirm the common clinical observation that patients with AHR often complain of dyspnoea, cough, chest tightness and/or wheezing upon exposure to stimuli such as irritants, cold air or exercise. Different factors may influence the perception of pharmacologically induced bronchoconstriction, including the speed and severity of the airway narrowing, dynamic hyperinflation, obesity, airway inflammation and emotional status, among others ${ }^{18}$. Our results build on previous studies by showing that the onset of MIS may occur at very low levels of fall in FEV1, within the range of the within-day variation of the FEV1 in healthy subjects (Figure 2). This suggests that, in the initial steps of the bronchial challenge, the level of airway obstruction as assessed by the FEV1 did not fully explain the appearance of symptoms. This notwithstanding, the association between MIS and percent fall in FEV1 at end-test (Table 4) supports the view that the role of airway narrowing increased throughout the methacholine test.

A small group of methacholine responders $(n=6)$ denied MIS despite falls in FEV1 as large as $25 \%$. One possible explanation is that these subjects underreported their symptoms. However, the short recall time resulting from the fact that the questionnaire was administered immediately after the inhalation of methacholine makes this possibility very unlikely and suggests these subjects were actually poor perceivers of acute airway 
narrowing. Poor perceptiveness of bronchoconstriction in hyperreactive subjects has been reported previously in subjects undergoing investigation for asthma ${ }^{3,15}$ or recruited from the general population ${ }^{13}$. Factors such as older age, airway inflammation and lower baseline inflammation could explain our findings ${ }^{19}$. However, while we did not measure airway inflammation, no differences existed between ARs and SRs in age and baseline FEV1 (Table 1). Whatever the explanation, in practice, the important point is the identification of poor-perceivers themselves, as they may incur an increased risk of severe asthma attacks ${ }^{3,15}$.

Explaining methacholine-induced symptoms in non-responders is not straightforward. Surprisingly, we found SNRs to be strikingly similar to SRs in many clinical parameters including the proportion of subjects $(\sim 80 \%)$ in whom the methacholine-induced symptoms corresponded to the symptoms justifying referral; incidentally, this finding has been found to be associated with a positive test result ${ }^{4,5,14}$. In contrast, SNRs differed significantly from ANRs by having worse clinical parameters and milder AHR as detected by the methacholine concentration-response slope. The obvious question that arises from the above two comparisons is whether using the FEV1 as sole outcome measure in the methacholine test could have resulted in false negative tests in some SNRs. Indeed, other parameters such as, for instance, measures of airway resistance, have been reported to be more sensitive detectors of changes in airway calibre than the FEV1 $1^{20-22}$. To quote but one study, Khalid and colleagues ${ }^{22}$ found that 27 of 138 subjects undergoing a methacholine test because of suspected asthma had a significant fall in sGaw (>52\%) but did not drop their FEV1 by $20 \%$. Secondly, for the methacholine test, a 12\% drop in FEV1 has been found to be more accurate than the $20 \%$ threshold in separating healthy controls from subjects with exercise-induced bronchospasm $^{23}$. Had we used the $12 \%$ value no fewer than 12 of our 16 SNRs would have turned into SRs. Finally, in the quality of global test, the FEV1 is not ideally suited to detect regional lung changes often associated with $\mathrm{AHR}^{24-26}$. Had they been present in our subjects, such changes could have explained both the clinical picture of SNRs and the poor correlation between wheezes - a sign produced locally in the central airways ${ }^{11}$ - and spirometry observed in SNRs and SRs (Table 2). However, since we did not measure regional lung function we can only speculate on this matter. 
Our study provides a good illustration of the limited application of PC20FEV1 as an index of severity in patients with MIS who failed to achieve a $20 \%$ fall in FEV1 during the methacholine test. Using the MCRS, we were able to demonstrate that the SNRs had milder AHR compared with the ANRs. This finding is compatible with results from prior studies demonstrating a significant relationship between airway responsiveness - assessed by the dose-response slope (DRS) - and asthma symptoms at sub-threshold levels of AHR in both children $^{7}$ and adults ${ }^{8}$. With the MCRS, we were able to assign a measure of severity of bronchial responsiveness to the subjects with falls in FEV1 of between 5 and 19\% who otherwise would be merely classified as having normal responsiveness. Furthermore, in quality of continuous measure, the MCRS is better suited than a dichotomous index to monitor changes in airway responsiveness over time. This aspect has practical importance because we cannot rule out the possibility that the milder AHR in SNRs might be an early manifestation of airway inflammation carrying an increased risk of future asthma. Although only prospective, follow-up studies of SNRs can prove or disprove this hypothesis, there is evidence to suggest this might be the case. In one study, Khalid and colleagues ${ }^{27}$ found that 15 of 77 methacholine non-responders presenting asthma-like symptoms developed overt asthma over a 3-yr period; noticeably, $43 \%$ of patients with 10 to $20 \%$ decline in FEV1 during the MCT eventually developed asthma. More recently, Peiman and colleagues ${ }^{28}$ reported a marked improvement in asthma symptoms and the disappearance of wheeze in methacholine non-responders with clinically suspected asthma receiving treatment with high doses of inhaled fluticasone. However, as acknowledged by the respective authors, the above studies were somehow limited either by their retrospective design ${ }^{27}$ or by the lack of a control group ${ }^{28}$. Furthermore, none of the studies assessed airway responsiveness in nonresponders experiencing symptoms during the test (i.e. SNRs), so the significance of milder AHR in this population remains unclear.

We think methodological errors did not influence our results. First, we used a wellestablished method for the provocation challenge protocol along with the standard ATS questionnaire. Second, although subject blinding to the incremental nature of the MCT was not feasible, all patients lacked blinding so this factor cannot explain the observed betweengroup differences. Finally, one may argue that because methacholine is a direct stimulus, our results are not generalizable. However, a previous investigation in mild asthmatics showed 
that symptom perception did not differ appreciably during the early response to a direct stimulus - histamine - and two indirect stimuli namely antigen exposure and exercise ${ }^{29}$.

In conclusion, our study shows that symptom evaluation during the MCT helped identifying patients with milder AHR that would be overlooked by the PC20FEV1. Further prospective, longitudinal studies of SNRs should be conducted to determine the prognostic validity of this approach. To gather information on this matter, based on our results we planned a longitudinal, prospective study aiming to examine the effect of inhaled corticosteroids on SNRs outcomes ${ }^{30}$.
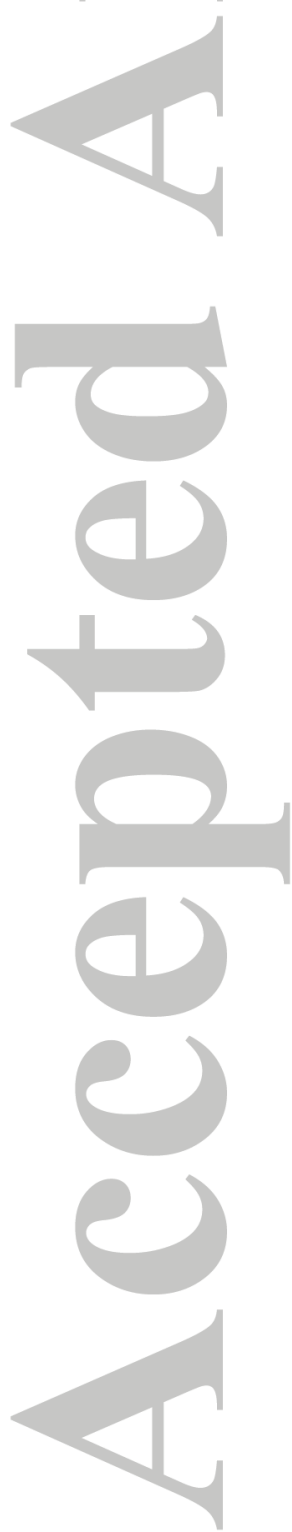


\section{Acknowledgements}

\section{Guarantor}

AB is guarantor for the study and takes responsibility for the integrity of all data and the accuracy of the data analysis

\section{Author contributions}

- $\mathbf{A B}$ contributed to the study design, data collection, data interpretation, drafting the manuscript, critical review of the manuscript and approval of the final version to be published.

PW contributed to the data analysis and interpretation, drafting the manuscript, critical review of the manuscript and approval of the final version to be published.

- GI contributed to the study design, data interpretation, drafting the manuscript, critical review of the manuscript and approval of the version to be published.

\section{Funding}

This study was supported by an unrestricted grant from Novartis Israel

\section{Financial/Nonfinancial disclosures}

- An unrestricted grant from GSK, Israel partially supports the respiratory research unit (RUPI).

\section{Role of the sponsors}

The sponsors had no role in the design of the study, the collection and the analysis of the data, or the preparation of the manuscript.

\section{Other contributions}

The authors thank Dr. L-P Boulet for critically reviewing an earlier version of the manuscript, Mrs. Ahouva Tasama for performing the methacholine challenge tests, and the patients for their participation

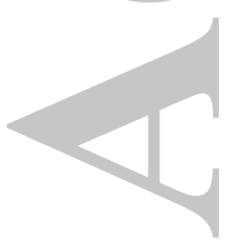


Table 1: Baseline characteristics of subjects groups classified by the occurrence of "asthmalike" symptoms during the challenge test and airway responsiveness

\begin{tabular}{|c|c|c|c|c|c|}
\hline & Non-responders & Responders & \multicolumn{3}{|c|}{ Odds Ratios } \\
\hline Symptomatic during MCT & No/Yes & No/Yes & $\begin{array}{l}\text { Association with } \\
\text { being symptomatic } \\
\text { during MCT }\end{array}$ & $\begin{array}{l}\text { Association with } \\
\text { being reactor }\end{array}$ & $\begin{array}{l}\text { Association with } \\
\text { being symptomatic } \\
\text { reactor }\end{array}$ \\
\hline $\mathbf{n}$ & $26 / 16$ & $6 / 34$ & & & \\
\hline Male & $58 \% / 81 \%$ & $67 \% / 35 \%$ & 0.68 & $0.33^{*}$ & $0.27^{* *}$ \\
\hline Mean Age [yrs.] & $38 / 32$ & $40 / 35$ & $0.89^{\mathrm{a}}$ & $0.99^{\mathrm{a}}$ & $0.96^{\mathrm{a}}$ \\
\hline Mean BMI [kg/m2] & $25 / 27$ & $25 / 26$ & $1.07^{b}$ & $1.00^{b}$ & $1.02^{b}$ \\
\hline Non-smoker & $62 \% / 69 \%$ & $83 \% / 62 \%$ & ref & ref & ref \\
\hline Smoker & $12 \% / 6 \%$ & $17 \% / 24 \%$ & 1.48 & 2.34 & 2.44 \\
\hline Ex-smoker & $27 \% / 25 \%$ & $-/ 15 \%$ & 0.84 & 0.47 & 0.69 \\
\hline Mean FEV1 [\% pred.] & $107 / 96$ & $105 / 96$ & $1.08^{\mathrm{c}^{* *}}$ & $1.03^{c}$ & $1.04^{\mathrm{c}^{*}}$ \\
\hline \multicolumn{6}{|l|}{ Reason for the test } \\
\hline Dyspnoea & $38 \% / 69 \%$ & $50 \% / 77 \%$ & $4.16 * *$ & $2.64 *$ & $3.25 *$ \\
\hline Cough & $38 \% / 25 \%$ & $-/ 32 \%$ & 0.94 & 0.76 & 1.16 \\
\hline Chest tightness & $4 \% /-$ & $-/ 3 \%$ & 0.63 & 1.05 & 1.42 \\
\hline Wheeze & $4 \% / 13 \%$ & $17 \% / 17 \%$ & 3.29 & 3.25 & 2.85 \\
\hline Rhinitis & $4 \% / 13 \%$ & $17 \% / 9 \%$ & 1.67 & 1.44 & 1.06 \\
\hline Bronchitis & $4 \% /-$ & $-/ 3 \%$ & 0.63 & 1.05 & 1.42 \\
\hline Job screening & $27 \% / 25 \%$ & $33 \% / 15 \%$ & 0.56 & 0.60 & 0.46 \\
\hline
\end{tabular}

${ }^{a} \mathrm{OR}$ by decade of increasing age

${ }^{\text {b }}$ OR by kg/m2

${ }^{c}$ OR by decreasing baseline FEV1 in \% predicted

$* \mathbf{p}<0.05, * * \mathbf{p}<0.01$ 
Table 2: Pre-challenge clinical characteristics $[\mathrm{n},(\%)]$ of subjects in the four groups

\begin{tabular}{|c|c|c|c|c|c|c|c|}
\hline \multirow[b]{2}{*}{ Symptomatic during MCT } & \multicolumn{2}{|c|}{ Non-responders } & \multicolumn{2}{|c|}{ Responders } & \multicolumn{3}{|c|}{$p$ values } \\
\hline & No & Yes & No & Yes & $\begin{array}{l}\text { Association } \\
\text { with being } \\
\text { symptomatic } \\
\text { during MCT }\end{array}$ & $\begin{array}{l}\text { Association } \\
\text { with being } \\
\text { responder }\end{array}$ & $\begin{array}{c}\text { Association } \\
\text { with being } \\
\text { symptomatic } \\
\text { responder }\end{array}$ \\
\hline n & 26 & 16 & 6 & 34 & & & \\
\hline \multicolumn{8}{|l|}{ Clinical history } \\
\hline Physician-diagnosed asthma & $2(7.7)$ & $10(62.5)$ & $\mathbf{0}(\mathbf{0 . 0})$ & $18(52.9)$ & 34.1** & 2.18 & $3.60 *$ \\
\hline Hospitalization for asthma & $1(3.8)$ & $1(6.2)$ & $\mathbf{0}(\mathbf{0 . 0})$ & $2(5.9)$ & 4.09 & 1.36 & 2.25 \\
\hline Respiratory dis. childhood & $2(7.7)$ & $5(31.2)$ & $1(16.7)$ & 7 (20.6) & 3.05 & 1.25 & 1.30 \\
\hline \multicolumn{8}{|l|}{ Recent symptoms ( 2 weeks) } \\
\hline Dyspnoea & $5(19.2)$ & $6(37.5)$ & $2(33.0)$ & $21(61.8)$ & $4.19 * *$ & $3.81 * *$ & $4.35 * *$ \\
\hline Cough & $11(42.3)$ & $8(50)$ & $1(16.7)$ & $23(67.6)$ & $2.72 *$ & 1.82 & $2.98 *$ \\
\hline Chest tightness & $3(11.5)$ & $3(18.8)$ & $0(\mathbf{0 . 0})$ & $10(29.4)$ & $3.40 ¥$ & 2.00 & $2.92 \S$ \\
\hline Wheeze & $1(3.8)$ & $4(250$ & $1(16.7)$ & $15(44.1)$ & $9.19 * *$ & $4.93 * *$ & $5.53 * *$ \\
\hline Any symptom & $14(53.8)$ & $12(75)$ & $3(50.0)$ & $28(82.3)$ & $3.53 *$ & 2.12 & $3.06 *$ \\
\hline Current/past medication & $4(15.4)$ & $8(50)$ & $2(33.0)$ & $21(61.8)$ & $5.98 * *$ & 3.38** & $3.92 * *$ \\
\hline
\end{tabular}

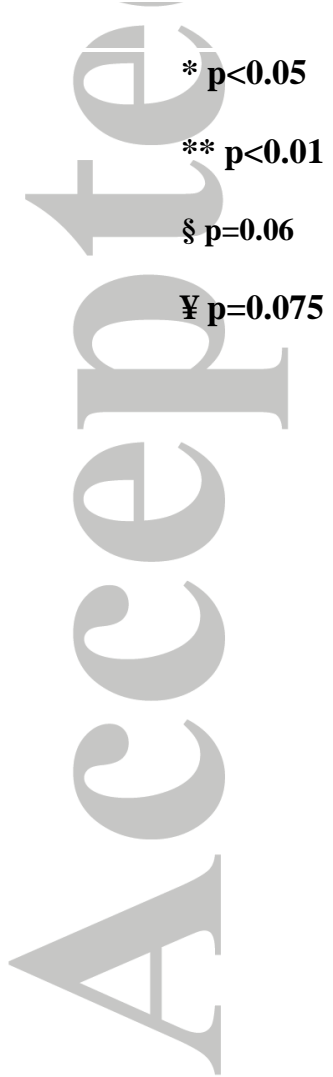


Table 3: Symptoms [n, (\%)] experienced during the methacholine challenge test by responders and non-responders

\begin{tabular}{|c|c|c|}
\hline Symptom & $\begin{array}{l}\text { SNRs } \\
(\mathrm{n}=16)\end{array}$ & $\begin{array}{c}\text { SRs } \\
(n=34)\end{array}$ \\
\hline Dyspnoea & $10(62.5)$ & $27(79.4)$ \\
\hline Cough & $4(25.0)$ & $9(26.5)$ \\
\hline Chest tightness & $2(12.5)$ & $6(17.6)$ \\
\hline Wheeze sounds detected by auscultation & $8(50.0)$ & $17(50.0)$ \\
\hline Wheezing reported by the patients & $2(12.5)$ & $7(20.6)$ \\
\hline $\begin{array}{l}\text { Patients considering the symptoms during the test similar to } \\
\text { those justifying referral }\end{array}$ & $13(81.2)$ & $27(79.4)$ \\
\hline
\end{tabular}

$\mathrm{p}$ value $=\mathbf{0 . 3 0 0}$ for dyspnoea and $\mathbf{1 . 0 0 0}$ for all other comparisons.

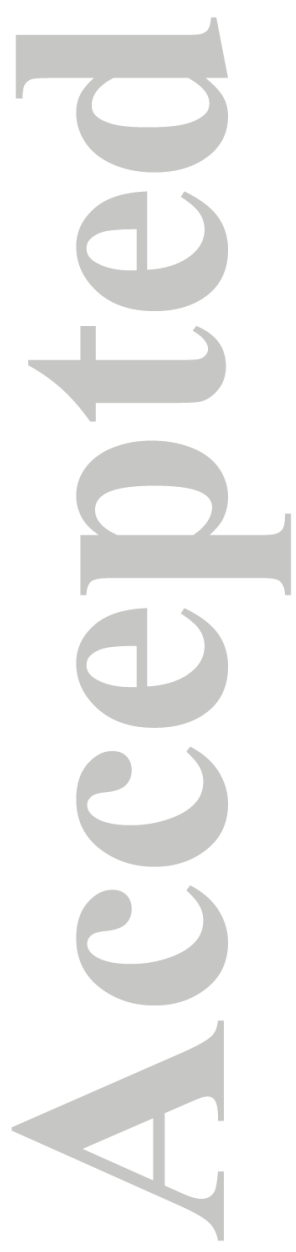


Table 4: Logistic model for the prediction of appearance of symptoms during the methacholine challenge test

\begin{tabular}{|l|c|c|c|c|c|}
\hline $\begin{array}{l}\text { Dependent } \\
\text { variable }\end{array}$ & \multicolumn{1}{|c|}{ Response variable } & $\begin{array}{c}\text { Odds } \\
\text { ratio }\end{array}$ & $\begin{array}{c}\text { Standard } \\
\text { Error }\end{array}$ & Z & p value \\
\hline $\begin{array}{l}\text { Symptom } \\
\text { during MCT }\end{array}$ & Physician-diagnosed asthma & 100.4 & 152.9 & 3.03 & 0.002 \\
\hline & Baseline FEV1 \% predicted & 1.114 & $\mathbf{0 . 0 4 6}$ & $\mathbf{2 . 6 4}$ & $\mathbf{0 . 0 0 8}$ \\
\hline & \% Fall FEV1 at end-test & 1.344 & $\mathbf{0 . 1 0 7}$ & 3.72 & $\mathbf{0 . 0 0 0}$ \\
\hline
\end{tabular}




\section{Legend to figures}

Figure 1: Proportion of responders according to the inhaled methacholine concentration at first symptom among subjects experiencing MIS. The numbers at each step correspond to the number of responders in whom symptoms first manifested either at that step or before. For instance, of the 10 subjects whose symptoms appeared at a methacholine concentration of $0.0625 \mathrm{mg} / \mathrm{mL}$ or earlier, $100 \%$ were responders. In turn, of the 23 subjects whose symptoms appeared at a concentration of $0.250 \mathrm{mg} / \mathrm{mL}$ or lower, $20(87 \%)$ were responders.

Figure 2: Scatter plot of percent fall in FEV1 vs. inhaled methacholine $(\mathrm{mg} / \mathrm{mL})$ at first symptom in responders and non-responders reporting MIS. A wide variation in the fall in FEV1 is seen in both responders (0-40\%) and non-responders ( 0-19\%). In 10 responders and 8 ,non-responders, asthma-like symptoms manifested at decreases in FEV1 $\sim 6 \%$ or lower.

Figure 3: Mixed model assessing airway responsiveness below the threshold of AHR by computing the slope of the methacholine concentration-response curve in SNRs and ANRs. The curves show that the fall in FEV1 was significantly greater in the SNRs across the challenge. Since responsiveness is defined by the ratio of fall in FEV1 to the amount of methacholine inhaled, for a given methacholine concentration the greater fall in FEV1 in SNRs indicates a relatively increased responsiveness in these subjects compared with the ANRs

Figure 4: Receiver operating characteristic curve (ROC) expressing the discrimination power of the logistic model presented in table 4 including, as dependent variable, the occurrence of asthma-like symptoms during the challenge and, as independent variables, physician-diagnosed asthma, baseline FEV1 in percentage of the predicted, and percent fall in FEV1 at the end of the challenge. The curve is displaced toward the left upper corner, giving an area under the curve (AUC) of 0.9511, indicating the excellent discriminant power of the model.

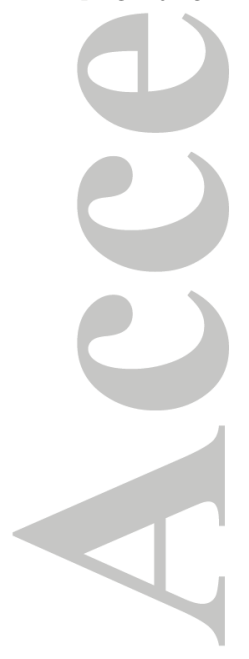




\section{References}

1. From the Global Strategy for Asthma Management and Prevention, Global Initiative for Asthma (GINA) 2015. Available from: http://www.ginasthma.org/.

2. Crapo RO, Casaburi R, Coates AL et al. American Thoracic Society. Guideline for Methacholine and Exercise Challenge Testing. Am J Respir Crit Care Med 2000; 161: 309-329

3. Boulet LP, Leblanc P, Turcotte H. Perception of scoring of induced bronchoconstriction as an index of awareness of asthma symptoms. Chest 1994; 105:1430-1433

4. Levesque M, Ghezzo H, L'Archeveque J, et al. Does the methacholine test reproduce symptoms? Can Respir J 2010;17:224-228

5. Stenton SC, Beach JR, Avery AJ et al. Asthmatic symptoms, airway responsiveness and recognition of bronchoconstriction. Respir Med 1995; 89:181-5.

6. Janssens T, Verleden G, De Peuter S et al. Predicting asthma outcome at diagnosis: The role of symptom perception during a histamine challenge test. $\boldsymbol{J}$ Asthma 2012; 49:230-236

7. G. de Meer, G.B. Marks, J.C. de Jongste et al. Airway responsiveness to hypertonic saline: dose-response slope or PD15? Eur Respir J 2005; 25: 153-158

8. Peat JK, Salome CM, Berry G et al. Relation of dose-response slope to respiratory symptoms and lung function in a population study of adults living in Busselton, Western Australia. Am Rev Resp Dis 1992; 146:860-865

9. Miller M.R., Hankinson, J., Brusasco, V. et al. Interpretative strategies for lung function tests SERIES “ATS/ERS TASK FORCE: STANDARDISATION OF LUNG FUNCTION TESTING”' Standardisation of Spirometry. EurRespir J 2005; 26: 319338

10. Bohadana $\mathrm{AB}$, Peslin $\mathrm{R}$, Uffholtz $\mathrm{H}$, et al. Potential for lung sound monitoring during bronchial provocation testing. Thorax 1995; 50: 955-961.

11. Bohadana A, Izbicki G, Kraman S. Fundamentals of lung auscultation. $\boldsymbol{N}$ Engl J Med; 2014; 370:744-751

12. Brand PLP, Rijken B, Schouten JP, et al. Perception of airway obstruction in a random population sample. Am Rev Respir Dis 1992; 146:396-401

13. Salome CM, Xuan W, Gray EJ, et al. Perception of airway narrowing in a general population sample. Eur Respir J 1997; 10:1052-1058

14. Devereux G, Hendrick DJ, Stenton SC. Perception of respiratory symptoms after methacholine-induced bronchoconstriction in a general population. Eur Respir J 1998; 12: 1089-1093

15. James AL, Carroll N, De Klerk N, et al. Increased perception of airway narrowing in patients with mild asthma. Respirology 1998; 3:241-245

16. Holgate ST, Beasley R, Twentyman OP. The pathogenesis and significance of bronchial hyperresponsiveness in airway disease. Clin Sci 1987; 73:562-572

17. O’Byrne PM, Inman MD. Airway hyperresponsiveness. Chest 2003; 123 (Suppl 3); 411S-416S

18. Cockroft DW, Davis BE. Mechanisms of airway hyperresponsiveness. J Allergy Clin Immunol 2006; 118: 551-9

19. Rosi E, Stendardi L, Binazzi B, et al. Perception of airway obstruction and airway 
inflammation in asthma: A Review. Lung 2006; 184:251-258

20. Nensa F, Marek W, Marek E et al. Assessment of airway hyperreactivity: comparison of forced spirometry and body plethysmography for methacholine challenge tests.

Eur J Med Res 2009; 14 (Suppl IV): 170-176

21. Bohadana AB, Peslin R, Megherbi S-E et al. Dose-response slope of forced oscillation and forced expiratory parameters in bronchial challenge testing. Eur Respir J 1999; 13:295-300

22. Khalid I, Morris ZQ, DiGiovine B.. Specific conductance criteria for a positive methacholine challenge test: Are the American Thoracic Society guidelines rather generous? Respir care 2009; 54:1168-1174

23. Eliasson AH, Phillips YY, Rajagopal KR, et al. Sensitivity and specificity of bronchial provocation testing. An evaluation of four techniques in exercise-induced bronchospasm. Chest.1992; 102(2):347-55.

24. Chapman DG, Berend N, King GG, et al. Increased airway closure is a determinant of airway hyperresponsiveness. Eur Respir J 2008; 32: 1563-1569

25. Zeidler MR, Kleerup EC, Goldin JG, et al. Montelukast improves regional airtrapping due to small airways obstruction in asthma. Eur Respir J 2006; 27:307-315

26. Farrow CE, Salome CM, Harris BE, et al. Airway closure on imaging relates to airway hyperresponsiveness and peripheral airway disease in asthma. J Appl Physiol 2012; 113:958-966

27. Khalid I, Obeid I., DiGiovine B., et al. Predictive value of sGaw, FEF25-75, and FEV1 for development of asthma after a negative methacholine challenge test. $\boldsymbol{J}$ Asthma 2009; 46;284-290

28. Peiman S., Abtahi H., Akhonzadeh S. et al. Fluticasone propionate in clinically suspected asthma patients with negative methacholine challenge tests. Clin Resp J; 2015; DOI:10.1111/crj.12353

29. Turcotte H, Corbeil F, Boulet L-P. Perception of breathlessness during bronchoconstriction induced by antigen, exercise and histamine challenges. Thorax 1990; 45:914-918

30. Bohadana, A; Wild P., Izbicki G. Effect of inhaled corticosteroid on methacholineinduced symptoms, airway responsiveness and $\mathrm{FE}_{\mathrm{NO}}$ levels in methacholine nonresponders: study protocol for a randomized controlled trial. (Submitted elsewhere). 


\section{Appendix}

SHAARE ZEDEK MEDICAL CENTER, JERUSALEM Study: "Asthma-like" symptoms during methacholine challenge test Principal Investigator: Abraham Bohadana, MD Methacholine Challenge Test Questionnaire

I) Identification Family name: Weight:

\section{NUMBER:}

First name:

BMI:

ID:
Age:

Sex:

Date:

\section{II) Reason for the test:}

\section{III) Pre-test Questionnaire:}

1. Has a physician told you that you have asthma?

2. Have you ever been hospitalized for asthma?

3. Did you have respiratory disease as a child?

4. Have you within the last two weeks ever experienced asthma symptoms such as? Wheezing yes no Chest tightness no

Cough yes no

Shortness of breath, yes no

5. If a smoker, when did you last smoke?

6. Have you had a respiratory infection in the last 6 weeks?

IV) Smoking

Never-smoker:

Smoker

Ex-smoker: cig/day since cig/day.

Started:

Quit:

VI) Post-methacholine inhalation questionnaire

1 . How are you feeling right now?
a. As before the inhalation
b. Better than before the inhalation
c. Worse than before the inhalation

V) Current respiratory medication because of:

2. If worse, this is because

b. Shortness of breath

c. Chest tightness

d. Wheezing

e. Other

VI) Past respiratory medication

3. Are the symptoms you feel now, similar to those you usually experienced (and for which you consulted)?

VII) Symptoms/Wheeze detection during the MCh challenge test

\begin{tabular}{|c|c|c|c|c|c|c|c|c|c|c|c|c|}
\hline Index & Baseline & $\mathrm{NaCl}$ & $\begin{array}{l}\text { MCh } \\
0.031\end{array}$ & $\begin{array}{l}\text { MCh } \\
0.0625\end{array}$ & $\begin{array}{l}\text { MCh } \\
0.125\end{array}$ & $\begin{array}{l}\text { MCh } \\
0.250\end{array}$ & $\begin{array}{l}\text { MCh } \\
0.50\end{array}$ & $\begin{array}{l}\text { MCh } \\
1.0\end{array}$ & $\begin{array}{l}\text { MCh } \\
2.0\end{array}$ & $\begin{array}{l}\text { MCh } \\
4.0\end{array}$ & $\begin{array}{l}\text { MCh } \\
8.0\end{array}$ & $\begin{array}{l}\text { Post- } \\
\text { BD }\end{array}$ \\
\hline Wheeze & & & & & & & & & & & & \\
\hline Symptoms & & & & & & & & & & & & \\
\hline FEV1 & & & & & & & & & & & & \\
\hline
\end{tabular}

Wheeze $=0$ or +

Symptoms $=0$ or + 


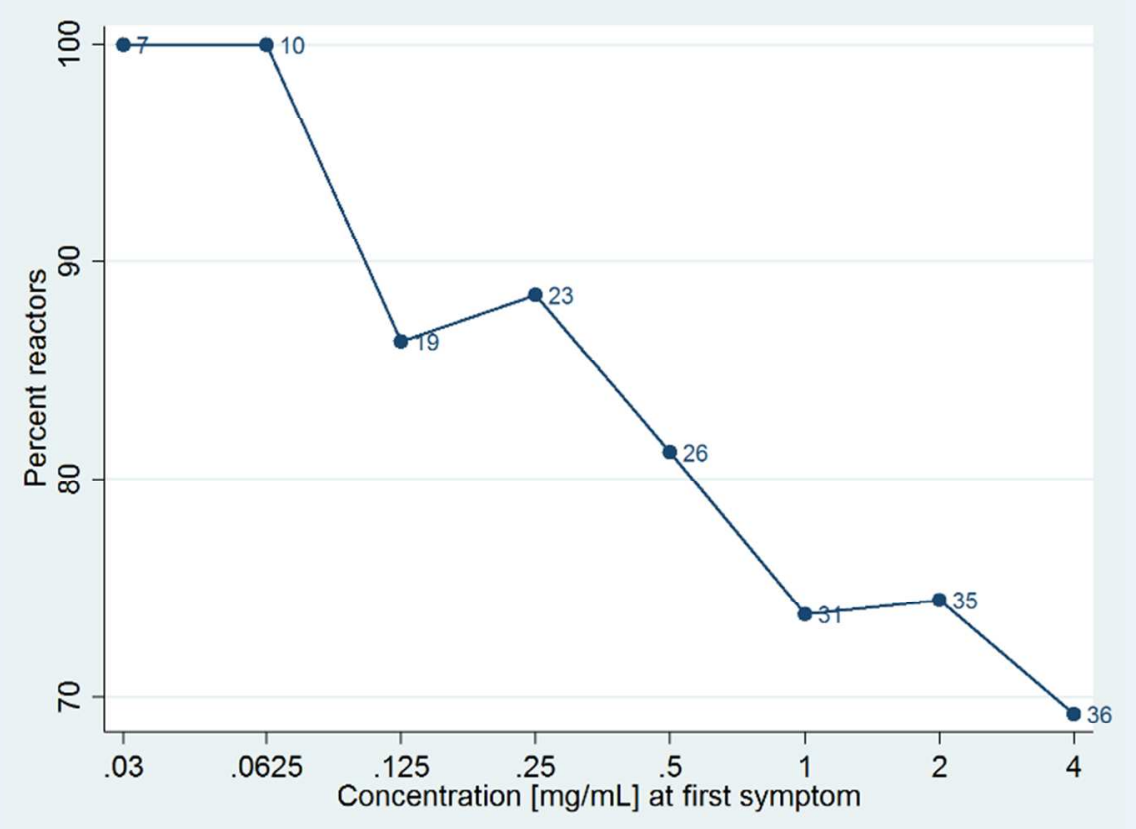

Figure 1. Percent of reactors according to the methacholine concentration at onset of symptoms in subjects experiencing MIS

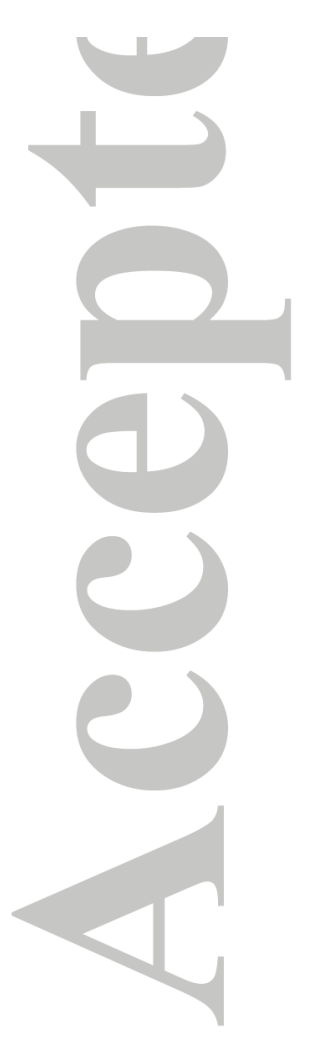

$243 \times 157 \mathrm{~mm}(300 \times 300 \mathrm{DPI})$ 


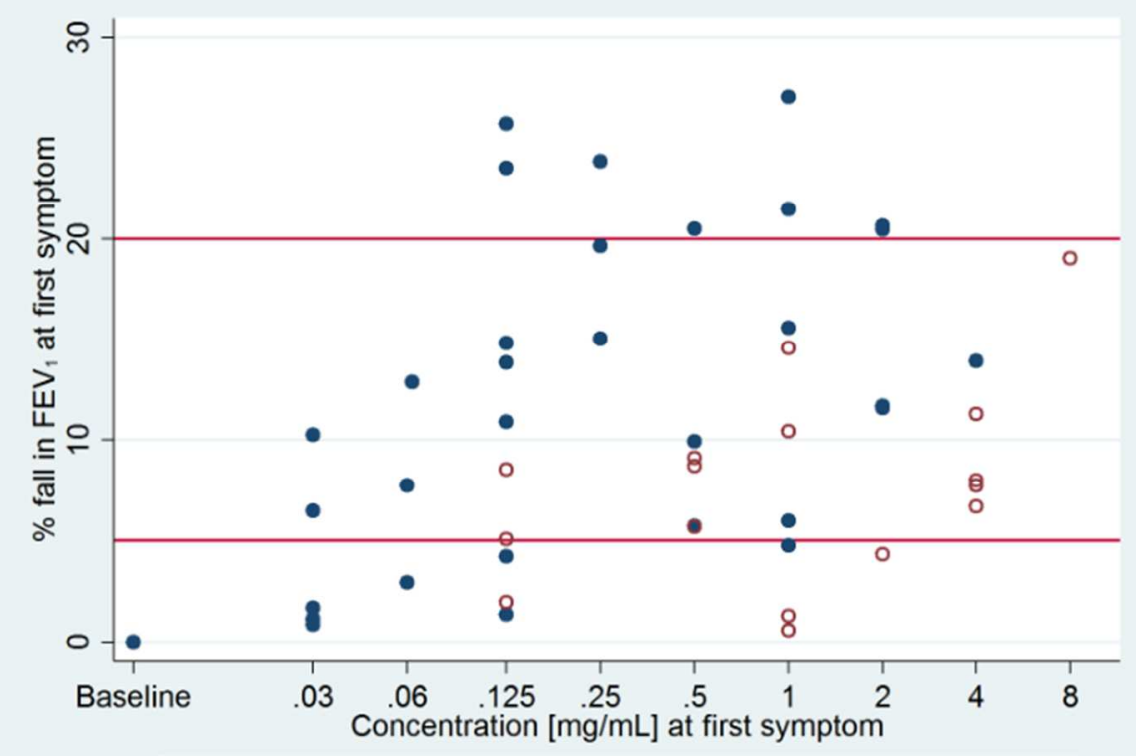

- Symptomatic responders $\circ$ Symptomatic non-responders

Figure 2. Percent fall of FEV1 at onset of MIS in responders and non-responders $210 \times 156 \mathrm{~mm}(300 \times 300 \mathrm{DPI})$

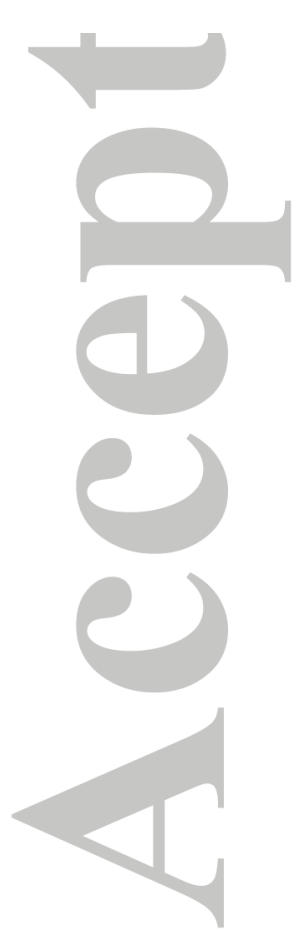

This article is protected by copyright. All rights reserved. 


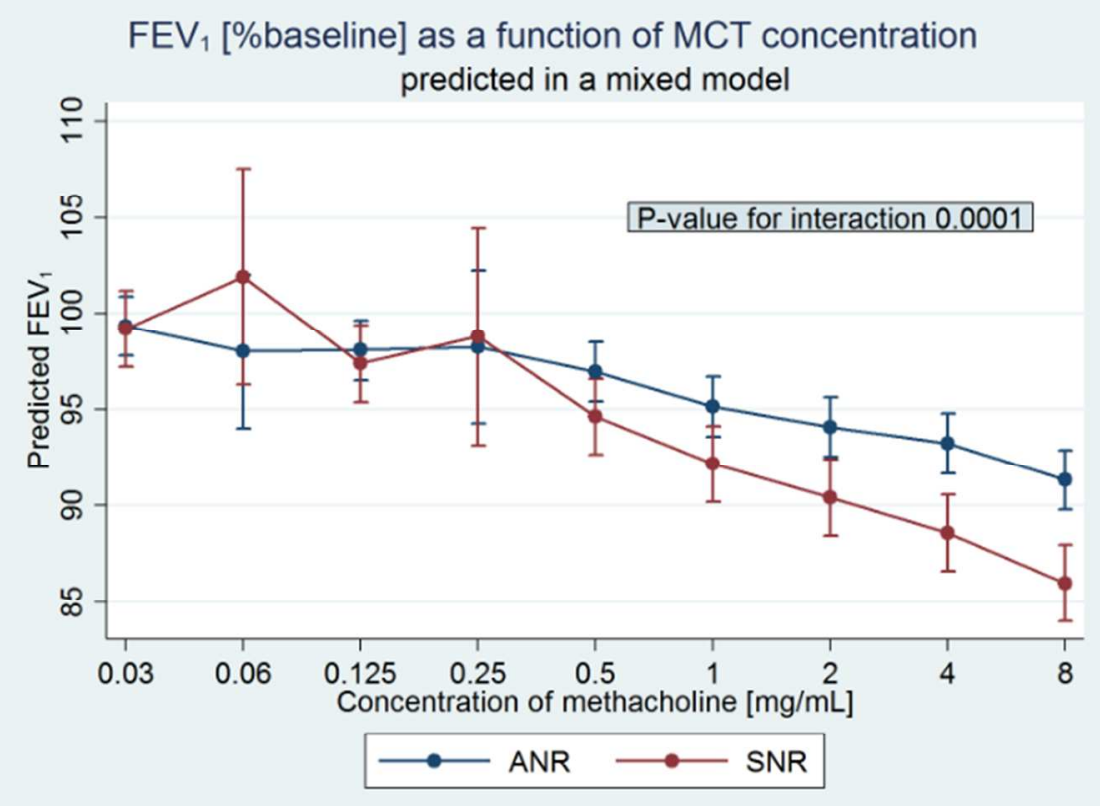

Figure 3. Assessment of airway responsiveness at sub-threshold levels of AHR in SNRs and ANRs. $215 \times 155 \mathrm{~mm}(300 \times 300 \mathrm{DPI})$ 
logistic regression for Symptom during MCT According to asthma, $\mathrm{FEV}_{1}\left[\%\right.$ pred], $\mathrm{FEV}_{1}$ at last concentration

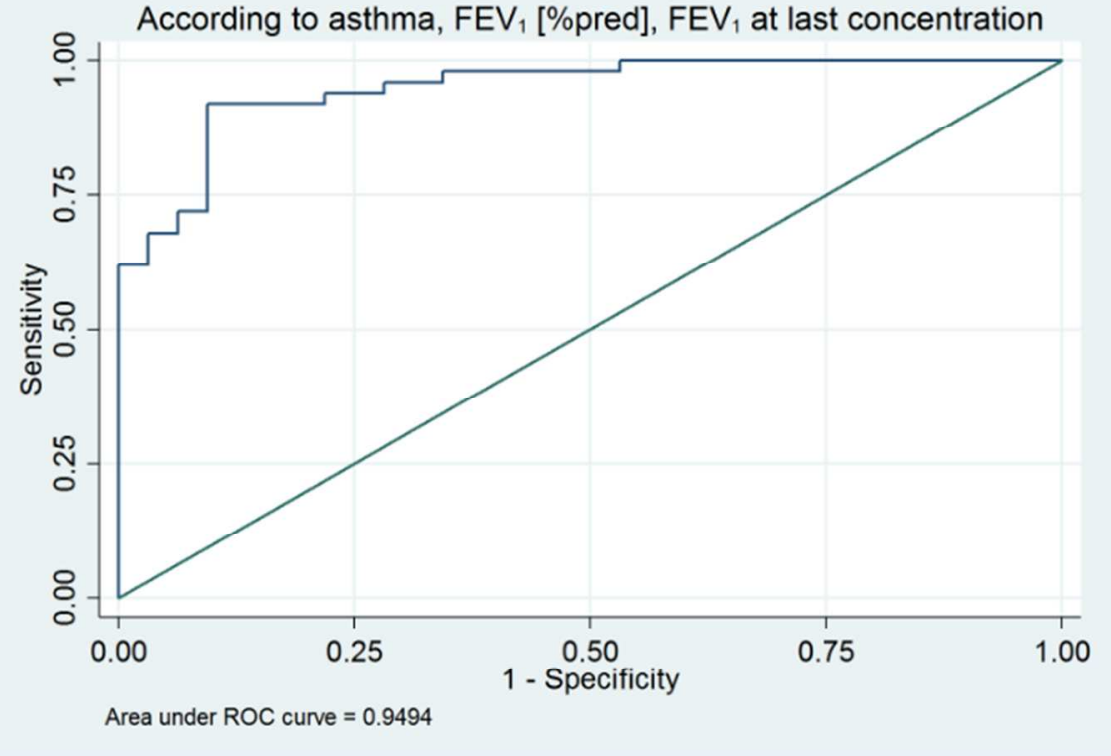

Figure 4. Discrimination of the logistic model assessed by means of receiver operating characteristic (ROC) curve

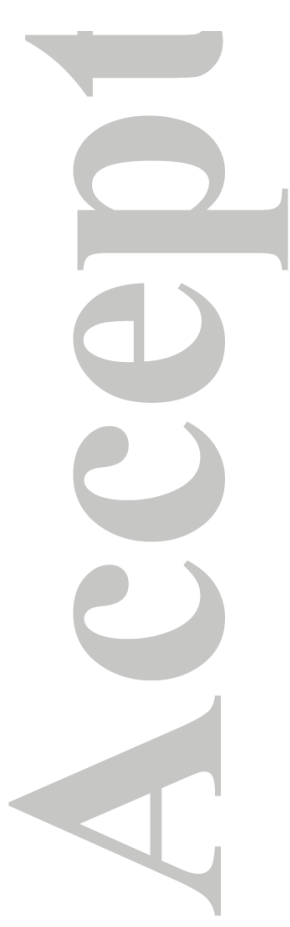

$215 \times 156 \mathrm{~mm}(300 \times 300 \mathrm{DPI})$ 